\title{
A multicalorimeter for the study of biological activity in marine sediments
}

\author{
Gerhard Graf $^{1}$, Volker Martens ${ }^{1}$, Wolfgang Queisser ${ }^{1}$, Peter Weinholz $^{2}$, Alexander Altenbach ${ }^{2}$ \\ ${ }^{1}$ Institut für Meereskunde, Düsternbrooker Weg 20, D-2300 Kiel 1, Federal Republic of Germany \\ ${ }^{2}$ Geologisch-Palaeontologisches Institut und Museum der Universität Kiel, Olshausenstr. 40, D-2300 Kiel 1, Federal Republic of Germany
}

\begin{abstract}
A multicalorimeter is described which allows the measurement of heat production of up to 10 sediment samples simultaneously. System regulation as well as data processing and evaluation are performed by personal computer. The instrument performs well even at non-controlled room temperature down to $-0.5^{\circ} \mathrm{C}$ on board a research vessel. First results from tests employing pressure chambers are presented. An example for a deep-sea heat-production profile is given from the Norwegian Basin, depicting subsurface maxima in benthic activity.
\end{abstract}

Direct microcalorimetry has been widely used in biological sciences (Wadsö 1975, Ljungholm et al. 1980, Gnaiger 1983, Lock \& Ford 1985). In biological oceanography the technique has been used for the investigation of anaerobic metabolism of benthic invertebrates (Pamatmat 1978, Famme \& Knudsen 1983, Shick 1981, Hammen 1983) and of soft bottom community metabolism (Pamatmat 1982). The method measures simultaneously all types of metabolism in a community; thus the rate of heat loss is enthalpy change and the last step of energy flow through the system. The combustion value of metabolized organic matter is equivalent to the released heat.

The method has been used to calculate carbon budgets (Graf et al. 1982, 1983). Recently, the reliability of these budgets was demonstrated by direct calorimetry of a predominantly anaerobic sediment (Graf 1987). By comparison, oxygen consumption, also called indirect calorimetry, only accounted for the topmost few millimeters of sediment activity and greatly underestimated the amount of metabolized organic matter in the lower layers.

Most calorimeters used are of the heat conduction type. These work isothermically and need long equilibration times (Calvet 1956), making direct calorimetry a relatively slow method. To overcome this problem, it is desirable to increase the number of devices in use simultaneously. An example is given by the Pamatmat double twin calorimeter (Pamatmat 1978). In the present article we present a multicalorimeter which can measure 10 samples simultaneously, thus enabling the measurement of a sediment heat flow profile in one run. Other features of the instrument for calorimetry of sediments have been improved. The multicalorimeter works at low temperature on board ship and accomodates larger samples than commercially available instruments. Furthermore the chambers can be compressed to simulate in situ pressure up to 310 bar.

Description of the instrument. The calorimeter block is placed inside a PVC-covered aluminium container (90 cm diameter) and fixed inside a well-insulated constant-temperature bath (Fig. 1). The aluminium container is completely submersed exept for PVC shafts through which samples are inserted into the instrument. Temperature is regulated by an external cooler (Braun, Frigomix 1497 and Thermomix 1480E), which is connected to a copper coil surrounding the container, and an internal heater (Braun Thermomix, 1480E), creating a accuracy of $\pm 0.005 \mathrm{C}^{\circ}$. A mixer increases turbulence in the water bath. It is possible to run the instrument at $-0.5^{\circ} \mathrm{C}$ at unregulated ambient room temperature.

The calorimeter block is constructed from about 200 $\mathrm{kg}$ of aluminium and has the shape of a 10-armed star (Fig. 2). Fig. 3 shows 2 sections of this construction. The left side depicts a tangential section through 2 arms including the PVC shaft for sample insertion and removal (8). The left arm holds a V4A-steel chamber $(6 \mathrm{~cm}$ external diameter) containing the sediment sam- 
Fig. 1. Temperature-regulating scheme of the multicalorimeter Extemal cooler (1) and internal heater (2) keep the calorimeter at constant temperature. Samples are introduced via the shafts (10)

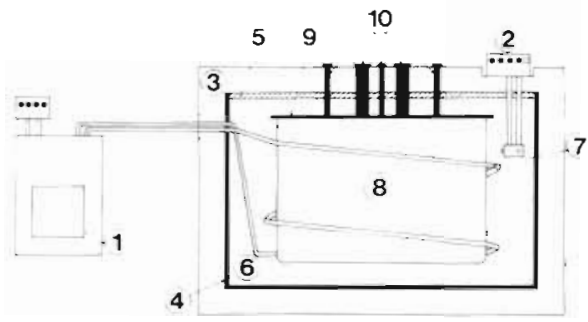

1 EXTERNAL COOLER

2 HEATER (THERMOMIX)

3 INSULATION

4 WATERBATH (PVC)

5 INSULATED COVER

6 WATER

7 COPPER COIL WITH

8 AL-CONTAINER

9 PVC-COVER

10 SHAFTS (PVO) ple while the right arm is empty. Chambers of varying heights can be accepted by rising or lowering an aluminium piston (4) from above via a fishing line. Maximum chamber height is $4 \mathrm{~cm}$, allowing a maximum sample size of about $70 \mathrm{~cm}^{3}$.

Since the calorimeter is run isothermically, the heat produced inside the steel chamber creates a temperature gradient from the sample towards the surrounding

\section{MULTICALORIMETER MEASURING AND EVALUATION SCHEME}

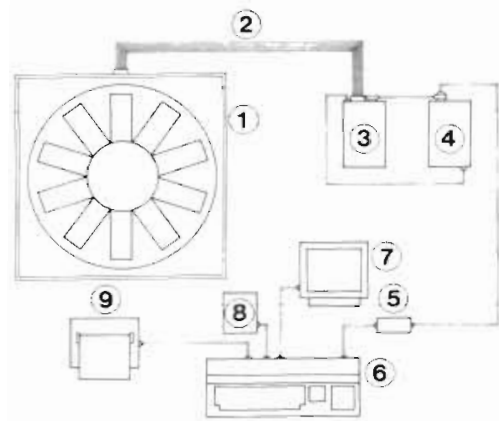

(1) MULTICALORIMETER

2 CABLE CONNECTION

3 SCANNER

4 NANOVOLTMETER

5 INTERFACE

IEEE BUS IV24

6. COMPUTER

7 MONITOR

8 DISK-STATION

9 PRINTER

Fig. 2. Measuring and evaluation scheme of the multicalorimeter

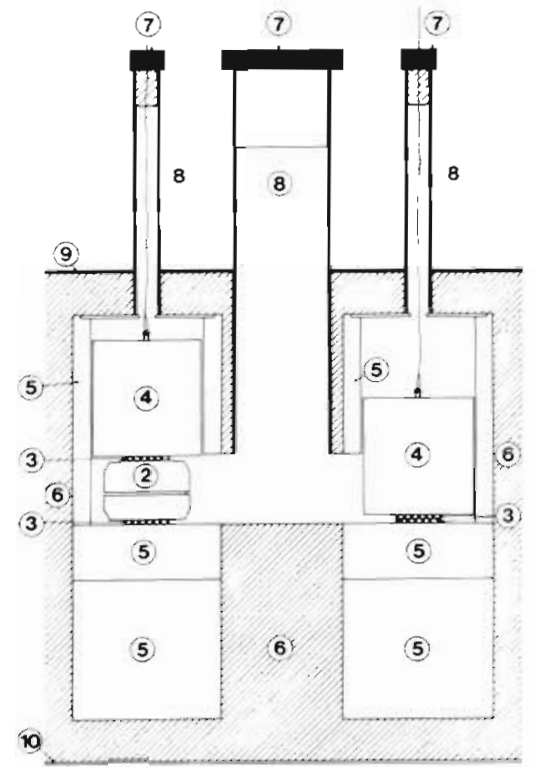

aluminium block (heat sink) (Fig. 3: 5) and thus a heat flow. This flow passes Peltier elements or thermopiles (Fig. 3: 3) (CP 1.4-71-10L, supplied by Walz, Effeltrich), which generate an electric current. The 2 Peltier elements contacting the chamber are connected in series, thus integrating the total heat flow from the steel chamber. In order to obtain a stabilized signal the Peltier elements are connected in series opposite to an identical set of Peltier elements in a compensation chamber located at the center of the calorimeter block. Fig. 3 (right side) shows a radial section of one arm including the central compensation chamber. This part of the multicalorimeter represents a twin calorimeter (Wadsö 1975).

Measuring and evaluation design. The thermopile voltage is measured by a micro- or nanovoltmeter (Keithley 195A or 181) (Fig. 2). A scanner (Keithley 705), controlled by a computer (Atari 520 ST+) switches successively from one arm to the next, always keeping the central chamber for compensation. Every $20 \mathrm{~min}$ each sample is measured for $2 \mathrm{~min}$. Because sediment thermograms change only slowly (Pamatmat 1983), continuous monitoring of the heat flow is not

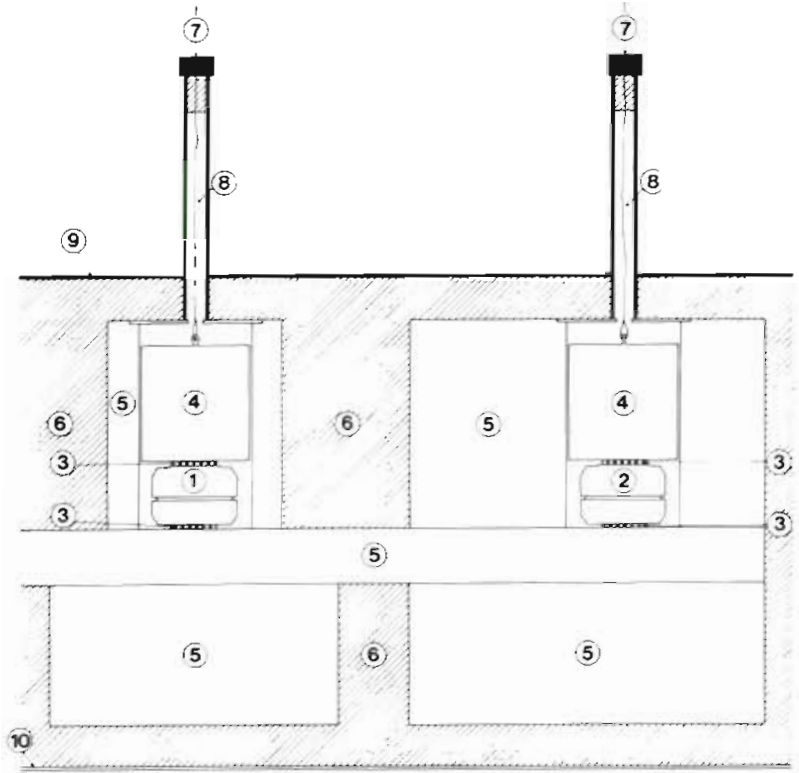

Fig. 3. Left: Tangential, and right: radial section through the calorimeter block. Chamber diameter is $6 \mathrm{~cm}$. Cable connections are not depicted 
necessary. During a run thermograms of each chamber can be viewed on the monitor Final evaluation, i.e. integration of the thermogram and correction for baselines, is done by the computer. All programs are written in ' $\mathrm{C}$ ' language. More details on the software are given by Altenbach \& Weinholz (1987). The calorimeter is calibrated by passing a current of 1 to $3 \mathrm{~mA}$ through a $50 \Omega$ resistor placed inside the steel chambers (cf. Berger 1969). Differences in the Peltier elements create different calibration factors for the 10 arms of between

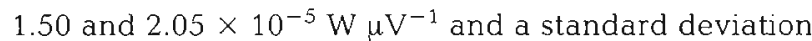
of one device of $\pm 1 \%$. Baseline drift is less than $1 \mu \mathrm{V}$ $\mathrm{d}^{-1}$ and can be monitored in one arm.

A critical aspect in the design of a multicalorimeter is avoidance of interactions between different heat flows from adjacent chambers. During a normal calibration run in one arm of the instrument there was no detectable signal in the other arms. Only if calibration heat was raised to a factor 1000 above sediment heat production was an effect of less than $1 \%$ visible, indicating that the heat sink is sufficient.

Case study. During 'Meteor' Cruise M/2 to the Norwegian Sea the multicalorimeter was tested on board and run at $-0.5^{\circ} \mathrm{C}$. Fig. 4 depicts the heat production of a sample from a deep-sea station in the Norwegian Basin (M/59; 65 31.0' N, 00 07.1' W) at $3062 \mathrm{~m}$ water depth using non-compressed chambers. A strong gradient is visible in the top $3 \mathrm{~cm}$ of the sediment, with 2 maxima in deeper sediment layers. These subsurface maxima were detected frequently during this expedition and will be discussed elsewhere. The absolute values, however, are comparable to shallow-water measurements (Graf et al. 1983). In comparison with a carbon supply of a few grams $\mathrm{m}^{-2} \mathrm{yr}^{-1}$ expected for this area the measured heatflow seems too high. One explanation is increased metabolic rate from decompression. At Station M/78 (70 00.4' N, $\left.00^{\circ} 04.1^{\prime} \mathrm{W}\right)$ at $3294 \mathrm{~m}$ water depth 2 special steel chambers with $10 \mathrm{~mm}$ thick walls were tested. The

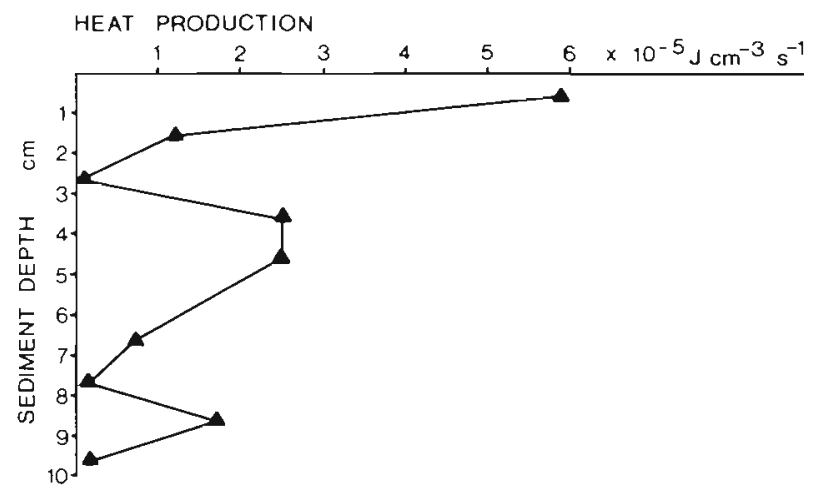

Fig. 4. Heat production profile of a deep-sea sediment from the Norwegian Basin chambers were connected to an HPLC pump and compressed to 310 bar with water overlying the sediment. Heat release of the sediment ( 0 to $2 \mathrm{~cm}$ ) decreased from 2.83 to $0.59 \times 10^{-5} \mathrm{~J} \mathrm{~cm}^{-3} \mathrm{~s}^{-1}$, a factor of 5 smaller. In the 2 to $4 \mathrm{~cm}$ layer the effect was less pronounced, decreasing from 1.30 to $0.77 \times 10^{-5} \mathrm{~J} \mathrm{~cm}^{-3} \mathrm{~s}^{-1}$. The values given in Fig. 4 thus give only decompressed heat production rates.

The instrument can measure heat flow of deep-sea samples at in situ pressure, but it remains to be seen if such rates are completely reversible after decompression.

Acknowledgements. We are indebted to Professor Dr S. Gerlach and Professor Dr M. M. Pamatmat for helpful comments on the manuscript. We also thank $\mathrm{H}$. Kähler for drafting the figures. This work was supported by the 'Deutsche Forschungsgemeinschaft' This is Publication No. 49 of SFB 313 of the University of Kiel.

\section{LITERATURE CITED}

Altenbach, A., Weinholz, P. (1987). GEM im Labor ST-Computer 5/1987: 75-78

Berger, R. L. (1969). Calibration and test reactions for microcalorimetry. In: Brown, H. D. (ed.) Academic Press, New York, p. 221-234

Calvet, E. (1956). Appareils et methods. Calvet, E., Prat, H. (eds.) In: Microcalorimetrie: applications physico-chimiques et biologiques. Masson, Paris, p. 5-136

Famme, P., Knudsen, J. (1983). Transitory activation of metabolism, carbon dioxide production and release of dissolved organic carbon by the mussel Mytilus edulis L., following periods of self-induced anaerobiosis. Mar Biol. Lett. 4: 183-192

Gnaiger, E. (1983). Microcalorimetric monitoring of biological activities. Ecological and toxicological studies in aquatic animals. Science Tools 30: 21-26

Graf, G. (1987). Benthic energy flow during a simulated autumn bloom sedimentation. Mar. Ecol. Prog. Ser. 39: $23-29$

Graf, G., Bengtsson, W., Diesner, U., Theede, H. (1982). Benthic response to sedimentation of a spring phytoplankton bloom: process and budget. Mar Biol. 67: 201-208

Graf, G., Schulz, R, Peinert, R., Meyer-Reil, L.-A. (1983). Benthic response to sedimentation events during autumn to spring at a shallow-water station in the Western Kiel Bight. Mar. Biol. 77: 235-246

Hammen, C. S. (1983). Direct calonimetry of marine invertebrates entering anoxic states. J. exp. Zool. 228: 397-403

Ljungholm, K., Noren, B., Odham, G. (1980). Microcalorimetric and gas chromatographic studies of microbial activity in water leached, acid leached and restored soils. Oikos 34 : 98-102

Lock, M. A., Ford, T. E. (1985). Microcalorimetric approach to determine relationships between energy supply and metabolism in river epilithon. Appl. environ. Microbiol. 49: $408-412$

Pamatmat, M. M. (1978). Oxygen uptake and heat production in a metabolic conformer (Littorina irrorata) and a metabolic regulator (Uca pugnax). Mar. Biol. 48: 317-325 
Pamatmat, M. M. (1982). Heat production by sediment: ecological significance. Science 215: 395-397

Pamatmat, M. M. (1983). Measuring aerobic and anaerobic metabolism of benthic infauna under natural conditions. J. exp. Zool. 228: 405-413

Shick, J. M. (1981). Heat production and oxygen uptake in intertidal sea anemones from different shore heights during exposure to air Mar. Biol. Lett. 2: 225-236

Wadsö, I. (1975). Microcalorimetry and its application in biological sciences. In: Pain, R. W., Smith, B. J. (eds.) New techniques in biophysics and cell biology. Wiley and Sons, London, p. 85-126

This note was submitted to the editor; it was accepted for printing on March 23, 1988 